\title{
Magnitude and factors associated with malnutrition in children 6-59 months of age in pastoral community of Dollo Ado district, Somali region, Ethiopia
}

\author{
Solomon Demissie ${ }^{1}$, Amare Worku ${ }^{2}$ \\ ${ }^{1}$ School of Public Health, College of Health Sciences, Haramaya University, Harar, Ethiopia \\ ${ }^{2}$ Addis Continental Institute of Public Health (ACIPH), Addis Ababa, Ethiopia
}

Email address:

Solx82@yahoo.com, solomondemissiek@gmail.com (S. Demissie)

\section{To cite this article:}

Solomon Demissie, Amare Worku. Magnitude and Factors Associated with Malnutrition in Children 6-59 Months of Age in Pastoral Community of Dollo Ado District, Somali Region, Ethiopia. Science Journal of Public Health. Vol. 1, No. 4, 2013, pp. $175-183$. doi: $10.11648 /$ j.sjph.20130104.12

\begin{abstract}
Background: Malnutrition at the early stages of life can lower child resistance to infections, increase child morbidity and mortality, and decrease mental development and cognitive achievement. Adequate nutrition is the keystone of survival, health and development not only of current generations but also of the ones to come. Child malnutrition is a major public health problem in Ethiopia. Objectives: To assess the magnitude and factors associated with malnutrition of children 6 to 59 months of age in Dollo Ado district, Somali region. Methods: A community based, cross-sectional study was conducted on 541 mother-child pairs of 6-59 month old children in December 2012. Anthropometric measurements of height and weight of 541 study children were taken with physical examination to identify the severe form of malnutrition and the socio-demographic characteristics of the subjects were collected using a questionnaire. Both anthropometric and non anthropometric data were entered using Epi-Info version 3.5.2. The data were analyzed using SPSS Version 16.0. Both bivariate and multivariate analysis (logistic regression model) was used to identify the determinants of child malnutrition. Results: Result of the study revealed that the overall prevalence of malnutrition in the community was high with $42.3 \%$ of the children being wasted, $34.4 \%$ for stunting and $47.7 \%$ for underweight. All three forms of malnutrition (wasting, stunting and underweight) was more prevalent among boys than girls with a statistically significant of $\mathrm{P}<0.031$. Prevalence of wasting was higher among young children while stunting and underweight were more likely to be observed in older children. Regression analysis shows that the significant determinants of malnutrition were gender and age of child, marital status, maternal education, monthly HH income, decision making, having of livestock, presence of ARI, total number of children ever born, health status during pregnancy, pre-lactation practice, mode of feeding, access to clean water and type of floor in the households. Conclusions: The prevalence of child malnutrition among the under five children was high, indicating that the nutrition situation in study area is very critical. Thus, malnutrition is a major public health problem. Further in-depth studies should also be encouraged to look for improved interventions.
\end{abstract}

Keywords: Child Malnutrition, Wasting, Underweight, Stunting, Magnitude, Cross-Sectional Studies, Associated Factor, Ethiopia

\section{Introduction}

Malnutrition continues to be a major public health problem in developing countries. It is the most important risk factor for the burden of disease causing about 300,000 deaths per year directly and indirectly responsible for more than half of all deaths in children [1,2,3,4].Malnutrition at the early stages of life can lower child resistance to infections, increase child morbidity and mortality, and decrease mental development and cognitive achievement and nutritional status is the best global indicator of wellbeing in children [6,7]. Adequate nutrition is the keystone of survival, health and development not only of current generations but also of the ones to come. Malnutrition is the largest single underlying cause of death worldwide and is associated with over $1 / 3$ of all childhood deaths $[8,9,10]$.

Malnutrition is an underlying cause of the death of 2.6 million children each year, and one-third of the global total of children's (7.6 million child) deaths each year before 
their fifth birthday through weakening the body's resistance to illness. Malnutrition is a silent killer that are under reported, under addressed and, as a result, under prioritized. Every hour and minute of every day, 300 and 5 children die because of malnutrition respectively. In the world today, one child in four is stunted due to malnutrition, and in developing countries this figure is as high as one in three and specifically in Africa two out of five children's will suffered with malnutrition [6].

Malnutrition is one of the leading causes of morbidity and mortality in children under five years of age in Ethiopia. The country has the second highest rate of malnutrition in Sub-Saharan Africa [11]. Malnutrition in children is one of the most serious public health problem in Ethiopia and the highest in the world $[4,12,13,14]$. According to the 2011 DHS of Ethiopia, the prevalence of underweight, stunting, and wasting was very high; $30.7 \%, 33 \%$ and $45.3 \%$, respectively for Somali region [5]. Somali region is one of the most underserved regions in terms of access to essential services and characterized by a high level of child malnutrition, food insecurity, and vulnerable livelihoods. Dollo Ado is a predominantly pastoral area known for its recurrent drought for several years. Therefore, identifying and understanding of the risk factors for child malnutrition in study area is important to guide public health planners and policy makers to design appropriate strategies and interventions to enhance nutritional status.

\section{Objectives}

\subsection{General Objective}

- $\quad$ To assess the magnitude and factors associated with malnutrition among children of age 6-59 months in the district of Dollo Ado, Somali region, Ethiopia

\subsection{Specific Objectives}

1. To determine prevalence of Stunting, Wasting \& Underweight among children of age 6-59 months

2. To identify determinants of child malnutrition in the study area.

\section{Methods}

Study area and period: The study was conducted in Dollo Ado Woreda, Liben Zone, Somalia Region, in December, 2012.

Study design: A community based cross-sectional quantitative study design was used to assess the magnitude and factors associated with malnutrition in children 6-59 months of age.

Source population: The source population was all children 6-59 months of age and their mothers in the district of Dollo Ado who lived in the study area for at least six months prior to data collection.

Study population: The study population was children 659 months of age living in the district (rural and urban) kebeles randomly included in the study who fulfilled the inclusion criteria and resided in the district.

Sampling and Sample Size: The sample size was calculated by using single population proportion determination formula: $n=Z(\alpha / 2)^{2} * p(1-p) / d^{2}$ by taking the regional prevalence of Somali region for underweight, wasting and stunting are $30.7 \%, 45.3 \%$ and $16.1 \%$ respectively (DHS 2011). A multi-stage random sampling technique was used to select the target population. The estimate of the sample in this study was desired to be precise at a confidence level of $95 \%$ and a margin of error of five percent. Accordingly, 600 children paired with their mothers were selected by considering a $5 \%$ non respondent rate. The total sample size was distributed among twelve kebeles in the study area according to the number of households in each kebeles.

Data Collection Methods and Instrument: A structured interview questionnaire and anthropometric measurements were used for the collection of quantitative data. Eight data collection team members, six data collectors and two anthropometric measurement recorder and two supervisors including the principal investigator were involved in the data collection. To assess the physical growth and nutritional status of the children, measurements of height and weight were taken of all of the children. These measurements were taken during the home visit. Salter hanging spring scales with graduations of $100 \mathrm{~g}$ and a capacity for $26 \mathrm{~kg}$ was utilized for measuring the weight of the children with minimum clothing and no shoes to the nearest $0.1 \mathrm{~kg}$. Recumbent length measurement was taken for children under two years of age while for children above two years stature was measured in a standing position in centimeters to the nearest of $0.1 \mathrm{~cm}$.

\section{Study Variables}

Dependent Variable: malnutrition indicated by wasting, stunting and an underweight status in children 6-59 months of age.

Independent Variables:

Five categories of factors were assessed as independent variables;

- Socio-economic and demographic variables; Age of child and mothers, child sex, family size, income, maternal/paternal education and occupation, marital status of the mother and number of livestock owned

- Child characteristics; height, weight, birth order, and childhood illness.

- Child caring practices; exclusive breast feeding, hygiene, health care seeking and immunization

- Maternal caring and characteristics; height, nutrition awareness, number of children ever born, ANC visits, pre-pregnancy weight, health status during pregnancy, use of extra food during pregnancy and autonomy in decision-making

- Environmental Health condition; water supply, sanitation and housing conditions

Data Quality Control and Management: The 
interviewers and supervisors were trained in data collection and measurement techniques for two days. Pre-test of questionnaires was done before the actual data collection work, which was not included in the study to see for the accuracy of responses, to estimate time needed and some modifications were made on the basis of the findings. Weighing scales was calibrated with known weight object regularly. The scales indicators were checked against zero reading after weighing every child. On daily basis collected information was reviewed and possible errors were returned to the data collectors for correction. Epi-info software was used to flag out of range values or errors while data processing. Data validity and reliability were maintained through close supervision of enumerators by the principal investigator.

Data processing and Analysis: Data entry and analysis was made using Epi-Info 3.5.2 and SPSS Version 16 respectively. Anthropometric indices were calculated using WHO Anthro 2007 software (version 2.0.4). Associations and correlations of the variables were computed using the Chi-square, OR and 95\% CI. P-value less than 0.05 were considered as statistically significant. Both bivariate and multivariate logistic regression analysis were used to identify the determinants of child malnutrition.

Ethical Considerations: Ethical approval for the research was obtained from the Addis continental institute of public health institutional research ethics review committee. Data collection was carried out after receiving ethical clearance letters from the woreda health and administration office. Informed verbal consent was obtained from each study subjects prior to data collection.

\section{Results}

Demographic and Socio-economic Conditions: A total of 541 children aged 6-59 months were participated in the study. The response rate was $99.4 \%$. Among the respondents, $372(68.8 \%)$ respondents were male headed. The median age of respondents was 28 and there were more women between the ages of 25 and 34 than any other age group. Almost all $99.1 \%$ of the study participants were Muslim, $0.7 \%$ were Orthodox while $0.2 \%$ were Catholic. Among those $96.3 \%$ from Somalia while 3.5\% from Oromo ethic group. Among the children studied, 263(48.6\%) and $278(51.4 \%)$ were boys and girls respectively, $230(42.5 \%)$ fell in the age group 12-23 months. The mean age of the child was 18.3 months. From the study it was observed that most $484(89.5 \%)$ of deliveries took place at home while $57(10.5 \%)$ of under five children were born in health institutions.

Among those mothers of the children who have been attend informal education shows that only 14(2.6\%) were can read and write and this indicates that majority of the respondents had no formal education. Average monthly income of the households in the study area was 900 birr.

Of the total 541 households interviewed during the study period, about $211(39 \%)$ of the respondents were owned livestock. The average number of livestock per HHs shows that a single HHs has 9.9 shoat, 3.9 Cattle and 2.1 camels.

Table1: Socio-demographic characteristics of the respondents in Dollo Ado District, June 2013

\begin{tabular}{|c|c|c|}
\hline Variable $(N=541)$ & Frequency & Percent \\
\hline \multicolumn{3}{|l|}{ Head of HH } \\
\hline Male & 372 & 68.8 \\
\hline Female & 169 & 31.2 \\
\hline \multicolumn{3}{|l|}{ Marital status } \\
\hline Married & 494 & 91.3 \\
\hline Divorced & 33 & 6.1 \\
\hline Widowed & 14 & 2.6 \\
\hline \multicolumn{3}{|c|}{ Maternal Education(basic education) } \\
\hline Yes & 49 & 9.1 \\
\hline No & 492 & 90.9 \\
\hline \multicolumn{3}{|l|}{ Ethnicity } \\
\hline Somalia & 521 & 96.3 \\
\hline Other* & 20 & 3.7 \\
\hline \multicolumn{3}{|l|}{ Religion } \\
\hline Muslim & 536 & 99.1 \\
\hline Other** & 5 & 0.9 \\
\hline \multicolumn{3}{|c|}{ Presence of Livestock } \\
\hline Yes & 211 & 39.0 \\
\hline No & 330 & 61.0 \\
\hline \multicolumn{3}{|l|}{ Monthly HH Income } \\
\hline$\leq 600$ & 138 & 25.5 \\
\hline $601-2000$ & 340 & 62.8 \\
\hline$>2001$ & 63 & 11.6 \\
\hline
\end{tabular}

N.B-Others include*Oromo, Amhara, ** Orthodox, Catholic

Prevalence of Common Childhood Illnesses: The common childhood illness reported to affect the health status of under five children were diarrhea, acute respiratory infections, measles and malaria. Among children under the age of five years, 215(39.7\%) of the respondents claimed diarrhea two weeks prior to the survey while acute respiratory illness and fever in the two weeks preceding the study were reported for $18.5 \%$ and $28.7 \%$ of all children respectively.

Child Feeding Practice: The study revealed that most mothers have almost similar feeding practices, 529(97.8\%) of the mothers were breastfeed on demand.Almost half of the mothers $311(57.5 \%)$ start breastfeeding immediately after birth. A majority $470(86.9 \%)$ of the mothers claimed they fed their child with colostrum immediately after birth. The exclusive breast-feeding rate for children 6 to 59 months of age was 26.4 percent.Pertaining to whether prelactation of foods while birth, 230(42.5\%) of the mothers initiated feeding their children with non breast milk prelacteal foods.

Maternal Characteristics and Practices: Among women studied, $13(2.4 \%)$ were 18 or younger years of age whereas $528(97.6 \%)$ of mothers were older than 18 years of age. On the other hand, $385(71.2 \%)$ of mothers gave first birth when they were younger than 18 years of age. Average total children born to a mother was 4.9 children (2.4 SD). Among those who had experienced at least one pregnancy, 
$392(72.5 \%)$ no extra food was taken from the usual time during pregnancy and lactation.

Nutritional Status of the Children: The overall malnutrition prevalence among under five children was $42.3 \%$ for wasting, $47.7 \%$ for underweight and $34.4 \%$ for stunting. In addition, the proportion of prevalence of malnutrition by its degree of severity $20 \%, 17.2 \%$, and $16.3 \%$ were severely underweight, stunting and wasting respectively. All the three types of malnutrition was more prevalent among boys than girls with a statistically significant of $\mathrm{P}<0.031$. Regarding O-edematous malnutrition, 50(9.2\%) under five children had bilateral Oedema with a statistical significant association with wasting and underweight $(\mathrm{P}=0.000)$. The highest proportion of wasting and underweight was 49.2 and $57.5 \%$, in the age group 6-11 and 24-35 months respectively while the highest proportion of stunting was $52.9 \%$ in the age group 36-47 months.

Analysis of Determinants of Child Malnutrition: To identify the determinants of malnutrition, binary logistic regression was performed. In the first step of logistic regression analysis, the risk factors found to be significantly related to wasting, stunting and underweight were analyzed and results of the multiple regression analysis for variables strongly linked to child malnutrition indicators are shown in table 2, 3, 4.Sex was one of the determinant variables which showed a significant association with wasting, stunting and underweight while child age had only a significant association with the status of stunting $(\mathrm{P}<0.05)$.

Determinants of Wasting: findings from the bivariate and multivariate analysis of the association between child caring practice and malnutrition showed that child sex, maternal education, monthly $\mathrm{HH}$ income, presence of ARI, time spent to collect water, possession of livestock, consumption of extra food during pregnancy, perception of the mother towards child weight at birth, prelacteal feeding practice and mode of feeding were significantly associated with wasting. The education level of the mother was also found to be one of the most important factors of malnutrition. Mother's education and prevalence of wasting were inversely related. Risks of being wasted were 0.4 times lower for children of mothers attended formal education compared to children whose mothers had no formal education. Family/household monthly income was significantly associated with wasting status of the under five children $(p=0.040)$. Children from household with middle and poor economic status were more likely to be wasted compared to children living in household with high household economic status. As the bivariate and logistic regression analysis shows that among common childhood illness, only presence of ARI in under five children was significantly associated with wasting $(\mathrm{COR}=1.8595 \%$ $\mathrm{CI}=1.19,2.87)$. The result of logistic regression analysis shown in the table 3 describes that children who had ARI in the preceding two weeks of the survey were 1.96 times higher risk of being wasted compared to those who are not suffered with $\mathrm{ARI}(\mathrm{AOR}=1.9695 \% \mathrm{CI}=1.20,3.18)$.
The study showed a significant association between child sex and the odds of being wasted was 1.69 times higher among male children than female children $(\mathrm{AOR}=1.6995 \%$ $\mathrm{CI}=1.16,2.45)$.

The study showed a significant association between child sex and the odds of being wasted was 1.69 times higher among male children than female children (AOR $=1.6995 \%$ $\mathrm{CI}=1.16,2.45$ ) while the risk of being wasted was 0.43 times lower for children who had live stock than those children they have not livestock (AOR $=0.43 \quad 95 \%$ $\mathrm{CI}=0.27,0.69)$. An interesting finding from this study, which is out of trend, is the risk of being wasted was 1.55 times higher among mother of children who consumed extra food during pregnancy than those mother of children who had not consumed extra food during pregnancy $(\mathrm{COR}=1.5595 \% \mathrm{CI}=1.06,2.26)$.

Determinants of stunting: The results of this study showed that child sex, child age, marital status, total number of children ever born, decision making, health status during pregnancy, source of safe water supply, having livestock, child care, and type of floor were significantly associated with stunting.

The analysis showed that male children were 1.48 times more likely to be stunted compared to female children $(\mathrm{COR}=1.5395 \% \mathrm{CI}=1.07,2.19)$. The risk of being stunted was 0.25 times, 0.34 times, and 0.48 times lower among children that were 6-11, 12-23 and 24-35 months of age than those older children (table 3 ). The odds of being stunted was 0.51 times lower among married women than divorced/widowed women $(\mathrm{COR}=0.5195 \% \mathrm{CI}=0.28,0.94)$. Children whose mothers had good health status during pregnancy were less likely to be stunted than children of mothers with not good health status during pregnancy ( $\mathrm{COR}=0.5195 \% \mathrm{CI}=0.28,0.94)$. House hold use safe water supply as main source of water supply, risks of being stunted were 0.49 times lower than for children uses unsafe water supply for human consumption (AOR $=0.49$ 95\% $\mathrm{CI}=0.32,0.75)$. Risks of stunting was 0.25 times lower for children who had live stock than those children they have not livestock $(\mathrm{AOR}=0.2595 \% \quad \mathrm{CI}=0.14,0.44)$. The likelihood of being stunted was also found to be 2.9 times higher among children whose house floor is earth than children who have a house with wooden type of floor $(\mathrm{AOR}=2.9395 \% \mathrm{CI}=1.23,6.97)$.

Determinants of underweight: Results for bivariate and logistic regression analyses indicate that child sex, marital status, maternal education, presence of health problems, and having of livestock were the only variables which were significantly associated with malnutrition in the study area $(p<0.05)$ (Table 4).The result of logistic regression analysis showed that male children were 1.7 times higher risk of being under-weighted as compared to female children $(\mathrm{AOR}=1.7095 \% \mathrm{CI}=1.15,2.51)$. Children among married women were less likely to be underweight compared to child mothers who did not married (divorced or widowed) ( $\mathrm{AOR}=0.4895 \% \mathrm{CI}=0.23,0.99$ ). The risk of being underweighted for children whose mother received or attend formal education is 0.17 times lower than children whose 
mothers who did not attend formal education $(\mathrm{AOR}=0.17$ $95 \% \mathrm{CI}=0.07-0.42)$. The likelihood of being under-weighted was found to be 0.08 times lower among children from
HHs having livestock compared with children of family who have not livestock ( $\mathrm{AOR}=0.0895 \% \mathrm{CI}=0.04,0.15)$.

Table 2. Bivariate and Logistic regression analyses showing the impact of selected variables on malnutrition as measured by wasting, Dollo Ado District, June 2013

\begin{tabular}{|c|c|c|c|c|}
\hline \multirow{2}{*}{ Variable } & \multicolumn{2}{|c|}{ Wasting } & \multirow{2}{*}{$\operatorname{COR}(95 \% C I)$} & \multirow{2}{*}{$\operatorname{AOR}(95 \% C I)$} \\
\hline & Yes & No & & \\
\hline \multicolumn{5}{|l|}{ Child Sex } \\
\hline Male & 127 & 136 & $1.58(1.12-2.23)^{*}$ & $1.69(1.16-2.45)^{*}$ \\
\hline Female & 103 & 175 & 1.00 & 1.00 \\
\hline \multicolumn{5}{|l|}{ Maternal Education } \\
\hline Attending basic education & 12 & 37 & $0.40(0.20-0.80)^{*}$ & $0.50(0.24-1.03)$ \\
\hline Not attending basic education & 218 & 274 & 1.00 & 1.00 \\
\hline \multicolumn{5}{|l|}{ Monthly Income } \\
\hline$\leq 500$ & 44 & 47 & $1.71(1.03-2.85)^{*}$ & $2.00(1.16-2.44)^{*}$ \\
\hline $501-1100$ & 119 & 141 & $1.54(1.05-2.27)^{*}$ & $1.60(1.06-2.41)^{*}$ \\
\hline$\geq 1101$ & 67 & 123 & 1.00 & 1.00 \\
\hline \multicolumn{5}{|l|}{ Pre-lactation practice } \\
\hline Yes & 116 & 114 & $1.75(1.24-2.48)^{*}$ & $1.66(1.10-2.49)^{*}$ \\
\hline No & 114 & 197 & 1.00 & 1.00 \\
\hline \multicolumn{5}{|l|}{ Material used to feed the child } \\
\hline Bottle & 98 & 167 & $0.86(0.49-1.52)$ & $0.76(0.40-1.44)$ \\
\hline Cup & 91 & 89 & $1.51(0.84-2.71)$ & $1.52(0.79-2.90)$ \\
\hline Spoon & 16 & 18 & $1.31(0.56-3.05)$ & $1.59(0.62-4.08)$ \\
\hline Others & 25 & 37 & 1.00 & 1.00 \\
\hline \multicolumn{5}{|l|}{ Presence of ARI } \\
\hline Yes & 55 & 45 & $1.85(1.19-2.87)^{*}$ & $1.96(1.20-3.18)^{*}$ \\
\hline No & 175 & 266 & 1 & 1 \\
\hline \multicolumn{5}{|l|}{ Time spent to collect water } \\
\hline$<15$ minutes & 61 & 48 & $2.10(1.17-3.75)^{*}$ & $1.93(1.02-3.65)^{*}$ \\
\hline 16-75 minutes & 137 & 210 & $1.08(0.66-1.76)$ & $1.29(0.76-2.21)$ \\
\hline$>76$ minutes & 32 & 53 & 1.00 & 1.00 \\
\hline \multicolumn{5}{|c|}{ Consumption of extra food during pregnancy } \\
\hline Yes & 75 & 74 & $1.55(1.06-2.26)^{*}$ & $1.46(0.94-2.26)$ \\
\hline No & 155 & 237 & 1.00 & 1.00 \\
\hline \multicolumn{5}{|c|}{$\begin{array}{l}\text { Perception of the mother towards child weight at } \\
\text { birth }\end{array}$} \\
\hline Thin & 54 & 83 & $1.02(0.67-1.55)$ & $1.08(0.69-1.68)$ \\
\hline Heavy & 8 & 8 & $1.57(0.57-4.31)$ & $1.05(0.35-3.10)$ \\
\hline Small & 25 & 21 & $1.87(1.00-3.50)$ & $1.98(1.01-3.88)^{*}$ \\
\hline Tall & 25 & 13 & $3.03(1.49-6.15)^{*}$ & $2.57(1.20-5.51)^{*}$ \\
\hline Normal & 118 & 186 & 1.00 & 1.00 \\
\hline \multicolumn{5}{|l|}{ Time initiation for CF } \\
\hline$\leq 6$ month & 110 & 126 & $1.34(0.95-1.89)$ & $1.33(0.91-1.94)$ \\
\hline$\geq 7$ month & 120 & 185 & 1.00 & 1.00 \\
\hline \multicolumn{5}{|l|}{ Livestock ownership } \\
\hline Yes & 34 & 88 & $0.44(0.28-0.68)^{* *}$ & $0.43(0.27-0.69)^{* *}$ \\
\hline No & 196 & 223 & 1.00 & 1.00 \\
\hline
\end{tabular}

${ }^{*} \mathrm{P}<0.05^{* *} \mathrm{P}<0.001$ 
Table 3. Bivariate and Logistic regression analyses showing the impact of selected variables on malnutrition as measured by Stunting, Dollo Ado District, June 2013

\begin{tabular}{|c|c|c|c|c|}
\hline Variable & $\begin{array}{l}\text { Stunting } \\
\text { Yes }\end{array}$ & No & COR $(95 \% \mathrm{CI})$ & $\operatorname{AOR}(95 \% \mathrm{CI})$ \\
\hline \multicolumn{5}{|l|}{ Child Sex } \\
\hline Male & 104 & 159 & $1.53(1.07-2.19)^{*}$ & $1.45(0.97-2.16)$ \\
\hline Female & 83 & 195 & 1.00 & 1.00 \\
\hline \multicolumn{5}{|l|}{ Child Age } \\
\hline 6-11 months & 32 & 100 & $0.30(0.16-0.56)^{* *}$ & $0.25(0.12-0.50)^{* *}$ \\
\hline $12-23$ months & 73 & 157 & $0.43(0.25-0.76)^{*}$ & $0.34(0.18-0.63)^{*}$ \\
\hline 24-35 Months & 48 & 65 & $0.69(0.37-1.27)$ & $0.48(0.24-0.94)^{*}$ \\
\hline$\geq 36$ months & 34 & 32 & 1.00 & 1.00 \\
\hline \multicolumn{5}{|l|}{ Marital status } \\
\hline Married & 164 & 330 & $0.51(0.28-0.94)^{*}$ & $1.04(0.43-2.52)$ \\
\hline Divorced/Widowed & 23 & 24 & 1.00 & 1.00 \\
\hline \multicolumn{5}{|c|}{ Total No. of children ever born } \\
\hline$\leq 3$ & 68 & 93 & $1.71(1.11-2.65)^{*}$ & $1.67(1.01-2.75)^{*}$ \\
\hline $4-5$ & 59 & 120 & $1.15(0.74-1.78)$ & $1.29(0.79-2.10)$ \\
\hline$\geq 6$ & 60 & 141 & 1.00 & 1.00 \\
\hline \multicolumn{5}{|l|}{ Decision Making } \\
\hline Mainly Spouse & 19 & 16 & 1.00 & 1.00 \\
\hline Mainly husband & 28 & 55 & $0.42(0.19-0.96) *$ & $0.41(0.18-0.94)^{*}$ \\
\hline Only husband & 40 & 99 & $0.34(0.15-0.72)^{*}$ & $0.32(0.15-0.70)^{*}$ \\
\hline Both Jointly & 100 & 184 & $0.45(0.22-0.92)^{*}$ & $0.43(0.21-0.89)^{*}$ \\
\hline \multicolumn{5}{|c|}{ Health status during pregnancy } \\
\hline Good & 92 & 215 & $0.62(0.43-0.89)^{*}$ & $0.75(0.49-1.14)$ \\
\hline Not good/sick & 95 & 139 & 1.00 & 1.00 \\
\hline \multicolumn{5}{|c|}{ Source of water supply } \\
\hline Unsafe water supply & 53 & 141 & 1.00 & 1.00 \\
\hline Safe water supply & 133 & 211 & $0.59(0.40-0.87)^{*}$ & $0.49(0.32-0.75)^{*}$ \\
\hline \multicolumn{5}{|l|}{ Livestock ownership } \\
\hline Yes & 21 & 101 & $0.31(0.19-0.52)^{* *}$ & $0.25(0.14-0.44)^{* *}$ \\
\hline No & 166 & 253 & 1.00 & 1.00 \\
\hline \multicolumn{5}{|l|}{ Who care the child } \\
\hline Mother & 146 & 292 & $1.12(0.64-1.97)$ & $1.08(0.57-2.02)$ \\
\hline Sister & 10 & 5 & $4.50(1.36-14.8)^{*}$ & $4.85(1.27-18.5)^{*}$ \\
\hline Grand Mother & 11 & 12 & $2.06(0.77-5.45)$ & $2.12(0.71-6.35)$ \\
\hline Servant & 20 & 45 & 1.00 & 1.00 \\
\hline \multicolumn{5}{|l|}{ Type of floor } \\
\hline Earth/Soil & 167 & 307 & $2.31(1.04-5.10)^{*}$ & $2.93(1.23-6.97)^{*}$ \\
\hline Ceramic/Cemented & 11 & 10 & $4.67(1.47-14.7)^{*}$ & $4.16(1.15-15.0)^{*}$ \\
\hline Wooden & 8 & 34 & 1.00 & 1.00 \\
\hline
\end{tabular}

Table 4. Bivariate and Logistic regression analyses showing the impact of selected variables on malnutrition as measured by underweight, Dollo Ado District, June 2013

\begin{tabular}{lllll}
\hline & Underweight & COR (95\% CI) & AOR(95\% CI) \\
\hline Child Sex & Nos & & & $1.70(1.15-2.51)^{*}$ \\
Male & 138 & 125 & $1.45(1.03-2.04)^{*}$ & 1.00 \\
Female & 120 & 158 & 1.00 & 1.00 \\
\hline
\end{tabular}




\begin{tabular}{|c|c|c|c|c|}
\hline & \multicolumn{2}{|c|}{ Underweight } & \multirow{2}{*}{$\operatorname{COR}(95 \% \mathrm{CI})$} & \multirow{2}{*}{$\operatorname{AOR}(95 \% \mathrm{CI})$} \\
\hline & Yes & No & & \\
\hline \multicolumn{5}{|l|}{ Marital status } \\
\hline Married & 228 & 266 & $0.48(0.26-0.90)^{*}$ & $0.48(0.23-0.99)^{*}$ \\
\hline Divorced/Widowed & 30 & 17 & 1.00 & 1.00 \\
\hline \multicolumn{5}{|l|}{ Maternal education } \\
\hline Basic education attended & 8 & 41 & $0.18(0.08-0.41)^{* *}$ & $0.17(0.07-0.42)^{* *}$ \\
\hline Not basic education attended & 250 & 242 & 1.00 & 1.00 \\
\hline \multicolumn{5}{|l|}{ Presence of health problems } \\
\hline Yes & 109 & 102 & $3.84(1.37-10.7)^{*}$ & $3.69(1.19-11.3)^{*}$ \\
\hline No & 144 & 163 & $3.18(1.15-8.78)^{*}$ & $2.93(0.96-8.95)$ \\
\hline Don’t Know & 5 & 18 & 1.00 & 1.00 \\
\hline \multicolumn{5}{|c|}{ Maternal Intake of extra food during pregnancy } \\
\hline Yes & 78 & 71 & $1.29(0.88-1.88)$ & $1.38(0.89-2.14)$ \\
\hline No & 180 & 212 & 1.00 & 1.00 \\
\hline \multicolumn{5}{|l|}{ Monthly HH Income } \\
\hline$<1000$ & 144 & 161 & $0.95(0.68-1.34)$ & $1.43(0.96-2.12)$ \\
\hline$>=1000$ & 114 & 122 & 1.00 & 1.00 \\
\hline \multicolumn{5}{|l|}{ Livestock ownership } \\
\hline Yes & 13 & 109 & $0.08(0.04-0.15)^{* *}$ & $0.08(0.04-0.15)^{* *}$ \\
\hline No & 245 & 174 & 1.00 & 1.00 \\
\hline
\end{tabular}

${ }^{*} \mathrm{P}<0.05^{* *} \mathrm{P}<0.001$

\section{Discussion}

The levels of underweight, wasting and stunting were $47.7 \%, 42.3 \%$ and $34.4 \%$, respectively. These prevalence rates of malnutrition indicated that the under five children of this study area were in a worst condition compared to malnutrition reported by a number of other studies [15]. The prevalence of wasting was relatively higher than the national figure while slightly lower than regional figures indicating a serious problem in the study area at the time of data collection. Although the prevalence rates of underweight was higher than the national figure as well as the regional prevalence. However, the prevalence of stunting is lower than that of the national figure and almost similar to the regional prevalence [5].High prevalence of wasting and underweight was a serious problem during data collection this could probably attributed to ARI, loss of assets especially livestock's, shortage of water due to recurrent drought or emergency situation at the time of data collection.

Child sex showed a significant association with wasting, stunting and underweight in this study. All three forms of malnutrition (wasting, stunting and underweight) were more prevalent among boys than girls. This could be attributed to the fact that boys are more vulnerable to health inequalities than their female counterparts in the same age groups [16] and increased attention being paid to female children, as well as reduced care and attention for older and weaned children [17].This finding is consistent with previous findings $[5,16,17,18,20,21,22]$. This probably often the care of children is closely linked with cultural and gender issues. In Somali society increased attention being paid to female children than male counterpart because of culture or traditional norms.

The prevalence of wasting was more prevalent in 611 months of children and the prevalence was decreases with age increases while the prevalence of stunting abruptly changed from 6-11 months of children to 36-47 months and similarly the prevalence of underweight increased from $43.2 \%$ in children $6-11$ months, to $45.2 \%$ in children between 12-23 months and to $57.5 \%$ in children older than two years of age. The results of this study are consistent with other findings [23].

Maternal education showed a significant association with wasting and underweight and it was higher among those children whose mothers were illiterate. This could be attributed to the fact that the overwhelming majority of the mothers in this study were illiterate and sample size was not adequate to detect differences. Similar findings are reported in other studies $[10,18]$.

Family/household income was significantly associated with acute malnutrition. A community based cross sectional study done in Gumbrit, Ethiopia showed family or household income was significantly associated with nutritional status of the under five children specifically wasting [25]. Similarly poor family income has been found as a risk factor for severe acute malnutrition in studies done in Nigeria. Likewise, another study argued that there is a significant association between house hold income and children's nutritional status $[13,14]$. 
This study revealed that wasting, stunting, and being underweight had a strong significant association with having of livestock among the family of the child. This is probably because the predominant and outstanding livelihood of the pastoral community is livestock. Similarly a study conducted in Ethiopia showed that ownership of livestock was associated significantly with wasting and underweight [24].

Among the childhood illness, ARI has a significant association with wasting. Recently a study conducted in Bangladesh confirmed that ARI has a strong association with acute malnutrition. This may be due to the fact that during drought there is a scarcity of food leading to under nutrition in children due to which they become more susceptible to diseases resulting higher morbidities.

A prelacteal feed is found to be associated with a higher risk of acute malnutrition. This finding agrees with past literatures that have shown that children who received prelacteal feeds more likely to be wasted [14].

The results of our study also demonstrate that there was a significant association between access to safe drinking water and child nutritional status especially stunting. This could be attributed to the fact that clean water will prevent the spread of water-borne diseases that can negatively affect the health and nutrition of young children. Access to unsafe water supply has been found as a risk factor for chronic malnutrition in studies done in Ethiopia[13,24], and Nigeria [17].Similarly a study done in introduction Guatemala showed that lack of safe water contributes significantly to the high incidence of chronic malnutrition.

Limitations of the study:

- As the study is cross-sectional in design, it neither represents seasonal variation of nutritional outcomes particularly to the wasting status nor establishes causal relationship.

- Qualitative aspects of data were not included in this study to explore some associated factors and to triangulate the finding of the quantitative study through qualitative data.

- As the study was questionnaire-based, questions that required a good memory were vulnerable to recall bias.

\section{Conclusions}

The finding of this study indicates that malnutrition is still an important major public health problem among children 6-59 months of age in Dollo Ado district. High prevalence rate of malnutrition (wasting, stunting and underweight) among the under five children were observed, indicating that the nutrition situation in study area is very critical. The figures in this study area were higher than the regional figures in the Ethiopian Demographic Health Survey 2011. Male children are more likely to become wasted, stunted and under-weighted than females. This finding confirmed that among the determinant factors; being male, child age, maternal education, marital status, and having of livestock remain key risk factors at least with two form of malnutrition. Planning and implementation of preventive policies aimed at addressing child malnutrition should also consider pastoral context based on these determinant factors.

\section{Recommendations}

Based on the findings of the study we recommend specific recommendations outlined below:

- Assessment and treatment of acute malnutrition through continuous nutrition and early warning information systems followed by response

- The ongoing therapeutic and targeted supplementary feeding program both at community level and school including de-worming and feeding programs

- Access to income through cash for work intervention and food aid programs with careful selection of beneficiaries until the food security situation of the community improves

- IEC that focused on the determinant factors identified to improve the health and nutritional status of children.

- The woreda health office and NGOs which are engaged in nutrition intervention among host Community should design integrated nutrition programs with special focus to male children.

- Health workers, experts \& local authorities must pay special emphasis to improve these conditions.

- Mainstream nutrition as a key component of health, WASH, livelihoods, food aid and education sectors as well as non government structures (NGOs).

\section{Acknowledgements}

The author would like to express his deepest appreciation to his advisor Dr. Amare Worku for his invaluable and unreserved advice and encouragement during his thesis work. Our sincere thanks are also extended to the publication office for giving the opportunity for abstract publication of this study. We also recognize the important role played by woreda health office in providing all study equipments and special thanks is due for data collectors and few friends for their support in the successful completion of this study. Last but not least, our gratitude goes to all the study participants in the sampled households for their paramount hospitality and cooperation to participate in the study.

\section{References}

[1] Olaf M. and Michael K. Malnutrition and health in developing countries: Canadian medical Association Journal, August 2, 2005; 173 (3)

[2] World Health Organization. Nutrition for health and development, protection of the human environment: 
Geneva.2005.

[3] Mercedes de Onis, Edward A. Frongillo, \& Monika Blossner. Is malnutrition declining? An analysis of changes in levels of child malnutrition since 1980; Bulletin of the World Health Organization, 2000, 78 (10)

[4] Melaku Umeta, Clive E. West, Hans Verhoef, Jemal Haidar and Joseph G.A.J. Hautvast: Factors Associated with Stunting in Infants Aged 5-11 Months in the Dodota-Sire District, Rural Ethiopia; American Society for Nutritional Sciences, Jornal of Nutrition, 31 December 2002

[5] Central Statistical Authority. Demographic and Health Survey 2011; Addis Ababa, Ethiopia and ICF International Calverton, Maryland. USA. March 2012.

[6] A life free from hunger: "Tackling Child Malnutrition," report by Save the children International, Geneva. Feb, 2012.

[7] Leonor Rodriguez, Elsa Cervantes and Rocio Ortiz. Malnutrition and Gastrointestinal and Respiratory Infections in Children: A Public Health Problem; Int. J. Environ. Res. Public Health 2011, 8, 1174-1205.

[8] World Health Organization. Communicable disease and severe food shortage technical Note: WHO, Geneva. October 2010.

[9] Ingunn MS, Thorkild T, Henry W, Charles K, and James KT. Determinants of infant growth in Eastern Uganda: a community-based cross-sectional study: BMC Public Health $2008,8: 418$

[10] Lisa C. Smith and Lawrence Haddad; Overcoming Child Malnutrition in developing Countries: Past Achievements and Future Choices; February 28, 2000

[11] FMOH. Program Implementation Manual of National Nutrition Program (NNP) I; 2008, A.A, Ethiopia.

[12] Gugsa Yimer. Malnutrition among children in Southern Ethiopia: Levels and risk factors .Ethiop. J. Health Dev. 2000;14(3):283-292

[13] Zewditu Getahun, Kelbessa Urga, Timotewos Ganebo, Ayele Nigatu. Review of the status of malnutrition and trends in Ethiopia. Ethiop. J. Health Dev. 2001

[14] Solomon Amsalu, Zemene Tigabu. Risk factors for severe acute malnutrition in children under the age of five: A casecontrol study. Ethiop.J.Health Dev 2008;22
[15] Uwem FE, Akin MO and Morenike AD. Prevalence of malnutrition among settled pastoral Fulani children in Southwest Nigeria :BMC Research Notes 2008, 1:7

[16] Henry W, Anne NA, Stefan P, James KT and Thorkild T. Boys are more stunted than girls in Sub-Saharan Africa: meta-analysis of 16 demographic and health surveys; $B M C$ Pediatrics 2007, 7:17

[17] Raphael OB, Funke IO, Segun BF, Foluke ES. Prevalence and Determinants of Malnutrition among Under-five Children of Farming Households in Kwara State, Nigeria: Canadian Center of Science and Education, Journal of Agricultural Science.2011;3(3).

[18] Luc Christiaenoen, Harold Alderman. Child malnutrition in Ethiopia; Can maternal knowledge augment the role of income: Africa Region Working Paper Series No. 22, Oct. 2001

[19] Ingunn M ,Stadskleiv E, Thorkild T, Henry W, Charles K, and James KT. Determinants of infant growth in Eastern Uganda: a community-based cross-sectional study: BMC Public Health 2008, 8:418

[20] Mahgoub S, Nnyepi M, Bandeke T. Factors Affecting Prevalence of Malnutrition Among Children Under Three Years of Age in Botswana. African Journal of Food Agriculture Nutrition and Development (AJFAND); Volume 6, 2006.

[21] Beka T, Wambui K., Zewditu G., \& Girum T.: Magnitude and determinants of stunting in children under five years of age in food surplus region of West Gojam, Ethiopia, Ethiop. J. Health Dev. 2009;23(2)

[22] Girmay M, Charlotte H, Michael D, Atalay A, Fikru T, Bogale W, Mark T, Martin P: Prevalence and predictors of under nutrition among infants aged six and twelve months in Butajira, Ethiopia: BMC Public Health. 2010;10:27

[23] Bobby J, Aaron R, Poonam K, and Vimal DR. Prevalence of Malnutrition in Rural Karnataka, South India: A Comparison of Anthropometric Indicators. J Health Population NUTR.2002; 20(3): 239-244.

[24] Alemu M, Nicola J, and Bekele T. Tackling child malnutrition in Ethiopia: Young lives project working paper No 19; Save the Children UK.2005.

[25] Melkie Edris. Assessment of Nutritional Status of Preschool Children of Gumbrit, North West Ethiopia: Ethiop.J.Health Dev. 2007; 21(2):125-129. 